Issn: 1808 - 799X

ano 12 , no $18-2014$

\title{
EDUCAÇÃO, EXPERIÊNCIA E EMANCIPAÇÃO: CONTRIBUIÇÕES DE E. P. THOMPSON PARA A HISTÓRIA DA EDUCAÇÃO
}

\author{
Alessandra Frota Martinez de Schueler ${ }^{1}$
}

\begin{abstract}
Como o capitalismo (ou seja, o mercado) recriou a natureza humana e as necessidades humanas, a economia política e seu antagonista revolucionário passaram a supor que esse homem econômico fosse eterno. (...) Nunca retornaremos à natureza humana précapitalista: mas lembrar como eram seus códigos, expectativas e necessidades alternativas pode renovar nossa percepção da gama de possibilidades implícita no ser humano. Isso não poderia até nos preparar para uma época em que se dissolvessem as necessidades e as expectativas do capitalismo e do comunismo estatal, permitindo que a natureza humana fosse construída de uma nova forma? (Thompson, 1998, p. 23).
\end{abstract}

\section{RESUMO}

O presente artigo tem o objetivo de destacar as contribuições da obra historiográfica de Edward Palmer Thompson para o ensino e a pesquisa no campo educacional, e, mais especificamente, para a área de História da Educação. Privilegio o enfoque sobre alguns aspectos de sua trajetória profissional e de sua prática teórica ativa no âmbito do materialismo histórico e da História Social inglesa, destacando algumas de suas reflexões sobre história, cultura, experiência, educação e emancipação. A produção do autor tem importância fundamental para os estudos que buscam compreender os processos históricos e as práticas educativas, as experiências e as lutas pela emancipação humana e a transformação social e política.

Palavras-chave: educação - experiência - História da Educação

1 Doutora em Educação pela Universidade Federal Fluminense. Professora de História da Educação no Programa de Pós-Graduação em Educação (campo de confluência Diversidade, Desigualdades Sociais e Educação, Linha de pesquisa História Social) e no curso de Pedagogia da mesma universidade. E-mail: alefrotaschueler@gmail.com. 


\title{
Trabalhonecessário
}

Issn: 1808 - 799X

ano 12 , no $18-2014$

\begin{abstract}
This article has the objective of stressing the contributions of the historiographical work of Edward Palmer Thompson to the teaching and research in the educational field and, more specifically, to the History of Educational field. I privilege the approach of some aspects of his professional trajectory and of his active theoretical practice in the scope of historical materialism and English Social History, highlighting some of his reflections on history, culture, experience, education and emancipation. The work of this author has fundamental importance to the studies that seek to comprehend the historical process and educational practices, the experiences and struggles for human emancipation and social and political transformation.
\end{abstract}

Key- words: education - experience - History of Education

O presente artigo origina-se de uma indagação que, há muito, tem acompanhado a mim e a muitos pesquisadores do campo educacional. ${ }^{2}$ Qual seria o lugar da educação na perspectiva historiográfica de E. P. Thompson? O que teria restado, na historiografia, da utopia socialista, emancipatória e humanista, de toda a prática teórica e do materialismo histórico produzido pela sua vasta obra?

Longe de pretender ensaiar uma resposta para a questão, tão aberta quanto o são a produção e o legado historiográficos do autor, no presente artigo meu objetivo é destacar alguns aspectos de sua trajetória profissional e de sua prática teórica ativa no âmbito do materialismo histórico e da História Social inglesa. Privilegio algumas de suas reflexões sobre história, cultura, experiência,

\footnotetext{
${ }^{2} \mathrm{O}$ texto é resultado de comunicação apresentada em mesa de debates no Seminário Trabalho, história e experiência de classe: Thompson 50 anos depois, a convite do Núcleo de Estudos, Documentação e Dados sobre Trabalho e Educação (NEDDATE/Universidade Federal Fluminense). A indagação sobre o papel da educação na trajetória e na produção acadêmica de E. P.Thompson foi retomada por mim, mais recentemente, em razão de minha participação numa das aulas da professora Lia Tiriba, quem, de maneira feliz e fértil, me provocou a breve reflexão apresentada neste artigo.
} 


\section{Trabalhonecessário}

Issn: 1808 - 799X

ano 12 , no $18-2014$

educação e emancipação. A hipótese aqui formulada é de que a perspectiva teórico-metodológica de E. P. Thompson tem importância fundamental para os estudos que buscam compreender os processos históricos, as práticas socioculturais e educativas, as experiências e as lutas pela emancipação humana e a transformação social e política na sociedade brasileira.

\section{Educação, cultura, experiência e emancipação}

A "educação do desejo" pela vida era essência do trabalho político e cultural de E. P. Thompson. A utopia de despertar os jovens, homens e mulheres comuns, para a vida, para a compreensão crítica de sua história e de sua ação concreta no mundo, esteve presente em todas as dimensões de sua experiência pessoal e profissional. Especialmente, a prática teórica e política na tradição crítica do materialismo histórico, e na militância no Partido Comunista (anos de 1940 a 1956), foram fertilizadas e encontraram amplo espaço na docência para classes de jovens e adultos trabalhadores. Na educação extramuros das Universidades (Leeds e Halifax), conveniadas com associações operárias britânicas, como a Worker's Education Association, trabalhou por quase duas décadas ininterruptas (1946-1963). Nesse lugar, segundo suas próprias palavras, ninguém lecionava por títulos ou por cargos, mas, sim em nome de um projeto de intervenção política e de transformação da sociedade (PALMER, 1996).

A experiência social e profissional na educação de adultos foi mediador fundamental para a construção teórica do autor no campo da historiografia. Operários, donas de casa, professores primários, funcionários de escritórios, bancários, viajantes, ativistas dos movimentos políticos e partidários, etc., compunham o quadro discente dos cursos e foram responsáveis pelo crescimento intelectual e humano, tanto de E. P. Thompson quanto de sua mulher, Dorothy Thompson, segundo declarações públicas de ambos, em várias oportunidades e relatórios de ensino (MATTOS, 2012).

TrabalhoNecessário - www.uff.br/trabalhonecessario; Ano 12, № 18/2014. 


\section{Trabalhonecessário}

Issn: 1808 - 799X

ano 12 , no $18-2014$

Esta temática foi retratada por ele no texto Educação e Experiência, publicado no Brasil em 2002, no livro Os Românticos. Resultado de uma de suas conferências, na Universidade de Leeds (1968), o artigo defende o argumento de que era preciso reconciliar a cultura letrada e a educação formal com a experiência comum, com a cultura do povo, restabelecendo, na prática educativa, a relação dialética entre professores e alunos. Na vivência pedagógica dos cursos de jovens e adultos, nos quais o historiador ministrava aulas de literatura e história inglesas, ele aprendeu tanto quanto ensinou. Ao mencionar a importância da dialética entre cultura letrada e experiência, o autor partilhava da concepção de que a educação humana, como uma prática social e cultural, não se confunde com a instrução formal, embora seja também uma das finalidades do sistema educacional historicamente constituído. A educação transcende as instituições formais, extrapola os limites da escola e da sala de aula, posto que se faz no conjunto das relações sociais.

\footnotetext{
"Toda educação que faz jus a esse nome envolve a relação de mutualidade, uma dialética, e nenhum educador que se preze pensa no material a seu dispor como uma turma de passivos recipientes de educação. Mas, na educação liberal de adultos, nenhum mestre provavelmente sobreviverá a uma aula - e nenhuma turma provavelmente continuará no curso com ele - se ele pensar, erradamente, que a turma desempenha um papel passivo. O que é diferente acerca do estudante adulto é a experiência que ele traz para a relação. A experiência modifica, às vezes de maneira sutil e às vezes radicalmente, todo o processo educacional; influencia os métodos de ensino, a seleção e o aperfeiçoamento dos mestres e o currículo, podendo até mesmo revelar pontos fracos ou omissões nas disciplinas acadêmicas tradicionais e levar à elaboração de novas áreas de estudo." (Thompson, 2002, p. 13)
}

Nessa perspectiva, não há nenhum desprezo pela escola ou pela formação intelectual institucionalizada. Contudo, pondera que a escola, ao se estruturar e se legitimar como uma instituição destinada a educar crianças e jovens, na Modernidade Ocidental, não age em um vazio cultural, mas numa situação de grande densidade cultural, na qual as pessoas são produzidas e reconhecidas como sujeitos na e da cultura. As sociedades humanas sempre produziram modos de significar e reconhecer suas práticas educativas. Os modelos

TrabalhoNecessário - www.uff.br/trabalhonecessario; Ano 12, №18/2014. 


\section{Trabalhonecessário}

Issn: 1808 - 799X

ano 12 , no $18-2014$

educacionais postos em ação pela forma escolar moderna dialogaram, de modo tenso, complexo e heterogêneo, com processos socioculturais e experiências educativas já existentes nas diversas classes sociais (GONDRA, SCHUELER, 2008). Para E. P. Thompson, longe de qualquer idealização, as dimensões de formação devem ser percebidas como estando intimamente relacionadas ao conjunto das experiências históricas dos sujeitos:

Os valores não são pensados, nem chamados, são vividos, e surgem dentro do mesmo vínculo com a vida material e as relações materiais em que surgem as nossas ideias. São as normas, as regras, as expectativas etc. necessárias e aprendidas (e aprendidas no sentimento) no habitus de viver; e aprendidas, em primeiro lugar, no trabalho e na comunidade imediata. Sem esse aprendizado a vida social não poderia ser mantida e toda a produção cessaria (Thompson, 1989, p. 358).

A crítica do historiador não visava a destituir a cultura letrada e a desvalorizar as instituições educacionais formais. Ao contrário, a sua militância na educação de jovens e adultos tinha a finalidade de remover a distância entre a cultura universitária e acadêmica e a cultura popular, das tradições e das experiências históricas da classe trabalhadora. Nesse aspecto, não poupava a intelectualidade e a academia de produzir e reiterar a separação, e o desprezo, desqualificando e hierarquizando os saberes, as práticas e as experiências de classe, mantendo o paradigma da "superioridade cultural" da classe dominante e dos intelectuais em face dos trabalhadores e das pessoas comuns:

grande parte do trabalho de um professor universitário é do tipo de um merceeiro intelectual, pesando e avaliando currículos de cursos, listas de livros para leitura, temas para ensaios, de acordo com determinado treinamento profissional. O perigo é que esse tipo de tecnologia profissional necessária seja confundida com autoridade intelectual e que as universidades - apresentado-se como um sindicato de "peritos" em cada ramo do conhecimento - expropriem as pessoas de sua identidade intelectual (Thompson, $2002 \mathrm{p}$. 43).

A crise e o distanciamento entre a experiência e a linguagem, entre a cultura popular e cultura letrada já havia sido apontada por Raymond Williams (2011 a; 2011 b) e Richard Hoggart (1957), pesquisadores do campo literário e

TrabalhoNecessário - www.uff.br/trabalhonecessario; Ano 12, №18/2014. 


\section{Trabalhonecessário}

Issn: 1808 - 799X

ano 12 , no $18-2014$

também educadores vinculados ao materialismo histórico e aos projetos de educação de jovens e adultos, dedicados aos estudos sobre cultura, as relações entre a literatura e a cultura popular, a oralidade e a escrita, a educação formal e a alfabetização na sociedade inglesa. Dialogando com seus companheiros de docência e militância política, E. P. Thompson argumentou que tal crise foi construída, pelo menos desde o século XVIII, no processo de fazer-se do capitalismo e da classe trabalhadora na Inglaterra. Analisando fontes literárias, folclóricas, jornais, folhetos, relatos e documentos diversos, o autor demonstrou que a tensão e o afastamento progressivo entre a cultura letrada e a experiência é herdada do arcabouço cultural iluminista, o qual se alicerçava, por sua vez, no caráter paternalista das relações entre as classes patrícia e plebeia na sociedade inglesa. Em termos gerais, o paternalismo presumia uma diferença qualitativa essencial entre a validade da experiência educada - cultura refinada - e a cultura dos pobres. A cultura de um homem, exatamente como seu prestígio social, era calculada de acordo com a hierarquia de sua classe. (p. 18)

Perspectivas questionadoras dessa distância também foram observadas no século XVIII, especialmente advindas do ideário iluminista radical. Nos anos revolucionários da Independência dos Estados Unidos (1776) e de Revolução Francesa (1789), a ideia paternalista de subordinação foi posta em revisão em nome dos princípios liberais que advogavam a igualdade de mérito e, de certo modo, a difusão da instrução primária entre as classes populares. No entanto, de acordo com o autor, o princípio da igualdade política, compreendida pela prática do sufrágio universal masculino, preponderou sobre a ideia radical da igualdade cultural humana. É verdade que no pensamento de alguns intelectuais e reformadores houve mudanças radicais no sentido de literatura que, à época, trouxeram a valorização da cultura popular, de sua formação moral e de sentimentos, de sua cultura e de seus valores sociais, notadamente entre literatos que estudavam e observavam a vida do povo. Alguns deles recrutados entre as classes populares, estes intelectuais chegaram a inverter a relação de

TrabalhoNecessário - www.uff.br/trabalhonecessario; Ano 12, № 18/2014. 


\section{Trabalhonecessário}

Issn: 1808 - 799X

ano 12 , no $18-2014$

superioridade, criando a representação de que a "vulgaridade" estava nos educados, pois a cultura popular seria o lugar do "sentimento real e da consciência justa". ${ }^{3}$ Nessa intelectualidade, analisada por Raymond Williams e E. P. Thompson em vários estudos, gestava-se o projeto político de aproveitamento e valorização da experiência popular, com o seu domínio prático sobre os saberes da natureza. Entretanto, ainda que se qualificasse positivamente a cultura popular, o sentimento, a vida interior, a experiência supostamente mais igualitária na vida e na relação humana, a solidariedade com o homem comum estava mais alicerçada nos atributos morais e espirituais do que propriamente no reconhecimento de sua racionalidade e capacidade intelectual.

No século XIX, o conservadorismo político e a expansão do capitalismo industrial reforçaram a ideia de superioridade intelectual das classes dominantes e da cultura letrada, produzindo representações negativas sobre a cultura popular e a experiência de vida dos pobres. O paternalismo, mudando a sua natureza, reforçava a busca de afastamento, notado nas políticas de controle social, por meio de assistência aos pobres, dos asilos e das sociedades de instrução e proteção. Temia-se, sobretudo, a autonomia, o autodidatismo dos trabalhadores, largamente observada no processo de formação da classe (fazer-se). Bibliotecas ambulantes, leituras nas tavernas, nas praças, nas sociedades de auxílio mútuo, o folclore, as tradições e as festas populares, e até mesmo as escolas metodistas, passaram a ser objeto de observação, e repressão, pelos poderes públicos. Não por acaso o século XIX, em todo o Ocidente, se caracterizou pela constituição da escola pública elementar como lugar legítimo de formação do cidadão. $O$ paternalismo antiquado visava manter os pobres sob suas normas e regras, de acordo com o princípio da subordinação. A partir de 1790, a "marcha do intelecto" - escolas metodistas, palestras para o povo, sociedades, ensino mútuo, institutos e instituições educacionais formais -, teriam sido responsáveis pela afirmação do

\footnotetext{
3 Expressão utilizada por Samuel Taylor Coleridge em Conciones ad Populum (1795), apud Thompson, 2002, p. 47.
}

TrabalhoNecessário - www.uff.br/trabalhonecessario; Ano 12, № 18/2014. 


\section{Trabalhonecessário}

Issn: 1808 - 799X

ano 12 , no $18-2014$

fosso entre a cultura letrada e a cultura do povo: "a educação se apresentava não apenas como uma baliza na direção de um universo mental novo e mais amplo, mas também como uma baliza para longe, para fora, do universo da experiência no qual se funda a sensibilidade" (Thompson, 2002, p. 25).

Ao longo dos séculos XIX e XX, os estudos de história da educação tem amplamente investigado a educação popular e a expansão da instrução pública no Ocidente, o impulso pela igualdade cultural permaneceu como bandeira de luta de intelectuais, educadores, classes trabalhadoras, movimento operário, e movimentos sociais heterogêneos, inclusive no Brasil. Mas, como argumentou $E$. P. Thompson, escrevendo nos final da década de 1960, de algum modo, ainda não superamos a representação da superioridade cultural e a distância entre experiência e educação, distância que se agravou, ainda mais, pelo progressivo caráter liberal, meritocrático, tecnológico e mercadológico, adquirido pelos sistemas educacionais capitalistas. A educação formal, majoritariamente percebida como uma "escada" a ser trilhada pelos indivíduos que a ela tiverem acesso, e que alcançarem o "sucesso" na apropriação dos códigos da cultura letrada, tornou-se um instrumento de mobilidade social seletiva, e, atualmente, mais uma mercadoria a ser consumida.

$\mathrm{Na}$ conferência aqui referida, e no conjunto das suas pesquisas historiográficas, o fato é que E. P. Thompson contribui para o campo educacional nos trazendo à tona a noção de experiência. Este termo implica, necessariamente, o reconhecimento dos sujeitos como reflexivos que, em suas ações, repõem continuamente o movimento da história. Para ele, "a experiência surge espontaneamente no ser social, mas não surge sem pensamento. Surge porque homens e mulheres (e não apenas filósofos) são racionais, e refletem sobre o que acontece a eles e ao seu mundo" (Thompson, 1981, p. 16). Segundo o autor:

TrabalhoNecessário - www.uff.br/trabalhonecessario; Ano 12, № 18/2014. 


\title{
Trabalhonecessário
}

Issn: 1808 - 799X

ano 12 , no $18-2014$

\begin{abstract}
O que descobrimos (em minha opinião) está num termo que falta: "experiência humana". É esse, exatamente, o termo que Althusser e seus seguidores desejam expulsar, sob injúrias, do clube do pensamento, com o nome de "empirismo". Os homens e mulheres também retornam como sujeitos, dentro desse termo - não como sujeitos autônomos,

"indivíduos livres", mas como pessoas que experimentam suas situações e relações produtivas determinadas como necessidades e interesses e como antagonismos, e em seguida "tratam" essa experiência em sua consciência e sua cultura (as duas outras expressões excluídas pela prática teórica) das mais complexas maneiras (sim,

"relativamente autônomas") e em seguida (muitas vezes, mas nem sempre, através das estruturas da classe resultantes) agem, por sua vez, sobre sua situação determinada (Thompson, 1981, p. 182.)
\end{abstract}

E. P. Thompson traz à tona outra questão fundamental para a pesquisa educacional, qual seja, a relação entre experiência e cultura. Para o historiador inglês, a cultura também pode ser descrita como uma "consciência afetiva e moral":

com "experiência" e "cultura", estamos num ponto de junção de outro tipo. Pois as pessoas não experimentam sua própria experiência apenas como ideias, no âmbito do pensamento e de seus procedimentos, ou (como supõem alguns praticantes teóricos) como instinto proletário etc. Elas também experimentam sua experiência como sentimento e lidam com esses sentimentos na cultura, como normas, obrigações familiares e de parentesco, e reciprocidades, como valores ou (através de formas mais elaboradas) na arte ou nas convicções religiosas. [...] Isso significa, exatamente, não propor que a "moral" seja uma "relação autônoma" da escolha e da vontade humanas, que surge independente do processo histórico. ... Pelo contrario, significa dizer que toda contradição é um conflito de valor, tanto quanto um conflito de interesse; que cada "necessidade" há um afeto, ou "vontade", a caminho de se transformar num dever (e vice-versa); que toda luta de classe é ao mesmo tempo uma luta acerca de valores (Thompson, 1981, p. 189-190).

A cultura é um vivo espaço no qual as experiências são vivenciadas e experimentadas. Neste universo, educação, instrução e formação podem ser adicionadas como ingredientes importantíssimos na vivência da cultura, compondo-se como experiências absolutamente presentes nas questões acerca de normas, obrigações e expectativas. Nos três volumes do The making of English work class (edição original de 1963) demonstrou como muitos artesãos, domésticos e outros trabalhadores, no seu tempo livre, às vezes às altas horas da noite, à luz de velas, dedicavam-se a uma cultura vigorosa, no seu processo de 


\section{Trabalhonecessário}

Issn: 1808 - 799X

ano 12 , no $18-2014$

fazer-se. ${ }^{4}$ Entre os elementos em desenvolvimento se destacavam o letramento, a instrução e a linguagem, muitas vezes adquiridos de forma autodidata. A educação e a cultura se desenvolvem também nas ruas, na imprensa, nos teatros e festas, na cultura oral, na aquisição de um saber utilitário e de uma política das ruas, tabernas e mercados. Textos das mais diversas naturezas eram lidos em voz alta para aqueles que não sabiam ler. E. P. Thompson afirma que esse saber cumpria um papel fundamental no desenvolvimento da consciência da classe operária daqueles anos iniciais do século XIX, uma vez que permitia o acesso dos mais pobres aos domínios culturais privilegiados de grupos dominantes (Thompson, 1989). Destaque-se que a maior parte dos elementos que constituiriam uma cultura intelectual rigorosa e vigorosa viria dos usos do tempo livre, não apenas das práticas de entretenimento, mas também como um tempo que permitia a fruição e a "exploração aberta do mundo" 5 .

O processo de formação -, que se insere em uma tentativa de compreensão e intervenção na cultura a partir das lentes próprias do sujeito que se forma, seja ele individual, seja coletivo -, não pode ser concedida, nem tutelada. O seu referente primeiro é a necessidade de autorreflexão crítica sobre as formas de organização da cultura. Implica uma vontade de conhecimento que visa, em ultima instância, ao desencantamento do mundo. E. P. Thompson nos lembra que a formação é um ato de autodeterminação, de autodisciplina. O "fazerse" e "formar-se" foram temas presentes na Formação da classe operária inglesa, tradução em português de making of the english working class. Neste estudo, o pesquisador procura ressaltar o movimento histórico perpetrado pelos próprios trabalhadores de se "autofazerem" como classe. Constata-se, assim, como que a

\footnotetext{
${ }^{4}$ Para o debate, utilizamos a obra traduzida por Denise Bottmann para o português: Thompson, E. P. A formação da classe operária inglesa: a força dos trabalhadores. Rio de Janeiro, Paz e Terra, 1987.

${ }^{5}$ Historiadores da educação brasileira tem contribuído para a reflexão sobre a relação entre educação, cultura, experiência e formação na obra do historiador inglês. Ver: Bertucci, Faria Filho, e Oliveira, 2010).
}

TrabalhoNecessário - www.uff.br/trabalhonecessario; Ano 12, № 18/2014. 


\section{Trabalhonecessário}

Issn: 1808 - 799X

ano 12 , no $18-2014$

educação participa da formação da classe e se forma ao mesmo tempo, pela ação dos trabalhadores (Thompson, 1987).

Analisou a formação da classe trabalhadora inglesa, desde 1790 até 1840 , culminando com a deflagração do movimento cartista, momento político no qual a classe trabalhadora consolidara-se enquanto tal. A obra trouxe à tona as experiências concretas da classe trabalhadora, entendidas como elementos fundamentais para a construção de uma consciência, embora escapando do antigo esquema essencialista presente nos conceitos de classe e de consciência de classe. Para E. P. Thompson a classe é sempre histórica, formada no movimento das lutas em uma dada sociedade:

Por classe, entendo um fenômeno histórico que unifica uma série de acontecimentos díspares, e aparentemente, desconectados, tanto na matéria-prima da experiência como na consciência. Não vejo a classe como uma "estrutura", nem mesmo como uma "categoria", mas como algo que ocorre efetivamente (e cuja ocorrência pode ser demonstrada) nas relações humanas. (...) a noção de classe traz consigo a noção de relação histórica. Como qualquer outra relação, é algo fluido que escapa à análise se tentarmos imobilizá-la num dado momento e dissecar sua estrutura. (...) A relação precisa estar sempre encarnada em pessoas e contextos reais. (THOMPSON, 1987, p. 9-12)

Nessa perspectiva, a classe, constituindo uma relação histórica, resulta da interação de alguns homens e mulheres em experiências comuns e compartilhadas, nas quais sentem e articulam interesses entre si, em oposição e contra outros homens e mulheres cujos interesses diferem e se antagonizam. A experiência de classe é determinada, em grande medida, pelas relações de produção em que os homens nasceram. Mas a consciência de classe vai além dessas mesmas relações, pois resulta das formas como tais experiências foram tratadas em termos culturais, no interior de tradições históricas, valores, ideias e formas institucionais: "Se a experiência aparece como determinada, o mesmo não ocorre com a consciência de classe. Podemos ver uma lógica nas relações de grupos profissionais semelhantes que vivem experiências parecidas, mas não podemos predicar nenhuma lei" (THOMPSON, 1987, p. 10).

TrabalhoNecessário - www.uff.br/trabalhonecessario; Ano 12, № 18/2014. 


\section{Trabalhonecessário}

Issn: 1808 - 799X

ano 12 , no $18-2014$

Com esses argumentos, por um lado, o autor criticava as correntes marxistas que julgavam ser a classe trabalhadora uma medida matemática, calculável em termos numéricos na relação direta com os meios de produção em uma sociedade. Tal perspectiva considerava inexistente a consciência de classe, na medida em que não encontrava entre os trabalhadores o modelo de organização que esperava: partidos políticos sólidos, sindicatos autônomos, interesses homogêneos definidos coletivamente. Por outro lado, ao compreender a classe como uma categoria histórica, forjada no interior de complexas relações e lutas sociais Thompson visava destruir as teses daqueles setores que, contrários às teorias materialistas, negavam a própria existência da classe.

Argumentando em favor da existência histórica da classe, E. P. Thompson propõe, ao mesmo tempo, uma reflexão teórica e uma metodologia de pesquisa:

“(...) Se detemos a história num determinado ponto, não há classes, mas simplesmente uma multidão de indivíduos com um amontoado de experiências. Mas se examinarmos esses homens durante um período adequado de mudanças sociais, observaremos padrões em suas relações, suas ideias e suas instituições. A classe é definida pelos homens enquanto vivem sua própria história e, ao final, esta é a sua única definição." (THOMPSON, 1987, p.10).

Se o trabalho sobre a formação da classe trabalhadora foi responsável pela sua projeção na academia, principalmente entre os grupos de pesquisadores vinculados à social history, não apenas na Grã Bretanha, também constituiu motivo e alvo dos críticos mais vorazes do historiador, destacando-se os próprios marxistas pertencentes ao Partido Comunista e/ou às universidades. Historiadores como Perry Anderson, Tom Nairn, e, com menores divergências Eric Hobsbawm, apontaram para o que denominaram "nacionalismo romântico". O apego e o respeito do autor à "árvore da liberdade" foi razão para que fosse acusado de liberal. A esses, respondia, retomando Marx e Engels: "a história é memória de uma cultura" e "jamais pode estar livre de paixões e comprometimentos. Não me sinto inibido de forma nenhuma pelo fato de que

TrabalhoNecessário - www.uff.br/trabalhonecessario; Ano 12, № 18/2014. 


\section{Trabalhonecessário}

Issn: 1808 - 799X

ano 12 , no $18-2014$

minhas próprias paixões e comprometimentos sejam evidentes". (THOMPSON apud PALMER, 1996, p. 125)

A resposta aos críticos veio, posteriormente em The poverty of theorie: or na orrery of errors, obra traduzida para o português e publicada no Brasil em 1981. O desmantelamento de Louis Althusser partiu do esforço do autor para afirmar positivamente o marxismo e o materialismo como uma importante teoria e uma prática necessárias às pesquisas acadêmicas e às lutas políticas. Remontando à tradição marxista, E. P. Thompson recorreu a polêmica de Marx versus Proudhon (The poverty of philosophy), de onde extraiu o título, sustentando a sua argumentação na ampla leitura dos textos do marxismo clássico e nas pesquisas de base materialista. Contestou a totalidade das premissas de Althusser, sua teologia e sua ideologia, principalmente a sua abordagem sobre a "falsa consciência". Reafirmou a importância do sujeito histórico - determinado e formado pela experiência - mas atuante nas suas relações históricas, na medida de suas possibilidades. Buscava estabelecer um equilíbrio entre as estruturas e as intervenções humanas, dos grupos e das classes sociais em luta, nos processos históricos (THOMPSON, 1981, p. 14-15) .

O diálogo entre teoria e prática, epistemologia e empiria, era uma reclamação e uma práxis constante em toda a extensa produção de E. P. Thompson. A sua opção teórica pelo materialismo histórico era confrontada, numa perspectiva dialética, com o material de pesquisa e as evidências históricas reais. Assim, o diálogo entre a teoria e a empiria tornava-se uma necessidade imperativa para uma produção histórica atenta ao rigor epistemológico, mas, ao mesmo tempo, aberta aos enigmas da história. Os processos históricos eram encarados a partir de seus contextos e de seus movimentos. Para ele - como argumentaria em um artigo dos anos 1980 sobre a necessidade de uma aproximação entre a história social e antropologia - a história era, sobretudo, contexto, processo e movimento. No artigo Folclore, antropologia e história social, defendeu a aproximação entre a história social e a antropologia. O objetivo do

TrabalhoNecessário - www.uff.br/trabalhonecessario; Ano 12, № 18/2014. 


\section{Trabalhonecessário}

Issn: 1808 - 799X

ano 12 , no $18-2014$

autor, nessa argumentação, consistia em resistir à utilização ingênua dos modelos teóricos antropológicos em uma aplicação de pesquisa historiográfica, pois a História "é a disciplina do contexto e do processo (...), todo significado é um significado no contexto, e quando as estruturas mudam, as formas antigas podem expressar funções novas, e as funções antigas podem encontrar expressão em formas novas" (THOMPSON, 2001, p.227).

Para E. P. Thompson, o modo de produção é uma totalidade, e possui uma centralidade no que diz respeito à formação da vida humana e da experiência social. No entanto, o modo de produção não se reduz ao econômico, mas compõe normas, valores e cultura. Lembrava que, se alguns teóricos alegam não existir produção sem economia, também sem cultura não pode haver produção.

Em um dos seus últimos textos, Customs in Commum, defendeu a tese de que a consciência e os usos costumeiros eram fortes na Inglaterra do século XVIII. Práticas costumeiras, mesmo algumas de invenção recente na moderna sociedade capitalista inglesa, foram traduzidas como reivindicações de antigas tradições culturais e como novos direitos. Os costumes e o direito consuetudinário constituíam, naquela época o que, atualmente, conhecemos sob uma perspectiva mais ampla de cultura, mas, estavam longe de serem estáticos e permanentes, sendo campos permanentes de disputas e conflitos sociais. Dialogando, mais uma vez, com os antropólogos, Thompson esclareceu a suas posições quanto aos termos cultura e "cultura popular":

uma cultura é também um conjunto de diferentes recursos, onde há sempre uma troca entre o escrito e oral, o dominante e o subordinado, a aldeia e a metrópole; é uma arena de elementos conflitivos, que somente sob uma pressão imperiosa - por exemplo, 0 nacionalismo, a consciência de classe ou a ortodoxia religiosa predominante - assume a forma de um sistema. (Thompson, 1998, p. 15-19)

A cultura - como, aliás, quaisquer instrumentos teóricos -, na ótica do historiador, não pode ser tomada como uma categoria fechada, e, muito menos, como expressão de uma estrutura, de um consenso social. Ao contrário, a cultura 


\section{Trabalhonecessário}

Issn: 1808 - 799X

ano 12 , no $18-2014$

se inscreve em contextos históricos específicos, no seio das lutas de classe e das relações materiais de poder, em sociedades determinadas. Por essa razão, a luta de classes é também uma disputa em torno de tradições e valores, regras morais, estéticas, religiosas, padrões familiares e sociabilidades - é uma luta entre culturas.

Da mesma forma, na sua análise sobre o Tempo, disciplina de trabalho e capitalismo industrial, também publicado em Costumes em Comum, E. P. Thompson investigou as transformações que o modo de produção capitalista em formação ocasionava nas relações de trabalho tradicionais, dinamitando o sistema de educação pela aprendizagem, as antigas relações entre artesãos-mestres e aprendizes nas corporações de ofício, visando modificar a percepção não somente do tempo, mas das formas de controle social e a totalidade da cultura. $\mathrm{O}$ processo de transformação dos significados e das práticas em torno do trabalho na sociedade capitalista que se gestava foi um longo processo de exploração, de resistência e de lutas, ao contrário da visão de linearidade presente nos modelos explicativos do desenvolvimento econômico e industrial.

\section{E. P. Thompson na historiografia educacional brasileira ${ }^{6}$}

Desde os anos de 1946, um grupo de historiadores marxistas, filiados ao Partido Comunista britânico, produzia reflexões em torno da validade das ferramentas teórico-metodológicas do materialismo histórico não apenas para a pesquisa e a produção historiográficas, mas, também para a renovação da ação e das práticas políticas de esquerda. A reflexão, em parte, relacionava-se ao contexto de uma profunda crise política e econômica, causadas pelas tensões e estragos do pós-guerra, pelo endurecimento do stalinismo soviético, sua violência

\footnotetext{
${ }^{6}$ As reflexões nesse item foram adaptadas de capítulo de livro que escrevi recentemente em parceria com Marcelo Mac Cord, intitulado História Social e História da Educação: as contribuições de Edward Palmer Thompson, que se encontra no prelo.
}

TrabalhoNecessário - www.uff.br/trabalhonecessario; Ano 12, № 18/2014. 


\section{Trabalhonecessário}

Issn: 1808 - 799X

ano 12, no $18-2014$

institucionalizada, e pelos expurgos aos "inimigos internos" dos partidos comunistas europeus, que ousavam discordar da ortodoxia oficial. Entre os historiadores militantes, Edward Thompson (1924-1993) foi um dos fundadores e integrantes da chamada New Left, juntamente com Cristopher Hill (1910-2003), Georg Rudé (1910-1993), Rodney Hilton (1916-2002), Eric Hobsbawm (1917), Dorothy Thompson (1923) e Raphael Samuel (1938-1996), apenas para citar alguns dentre os mais conhecidos historiadores sociais marxistas no Brasil (ANDERSON, 1985).

Como já argumentei anteriormente, estes autores, formados na experiência de militância política, nos movimentos sociais e na prática educativa com jovens e adultos, se destacaram pela investigação de temáticas inovadoras, que impunham ampla revisão da história social inglesa. Entre estas, sobressaíram-se aquelas relacionadas ao reexame do processo de industrialização e à revolução industrial dos séculos XVII e XVIII; às transformações econômicas e jurídicas sobre a propriedade e usos da terra, como a política de cercamentos; às Poor Laws e às políticas estatais de educação e controle social sobre as classes trabalhadoras; aos movimentos populares e operários e às suas lutas, desde os setecentos; à cultura e aos valores dos grupos populares; à história da educação, da literatura, das letras e do lluminismo entre os grupos operários e seus movimentos; às ações de contracultura e contra-hegemonia ocorridas em diferentes contextos históricos. Na maioria dos estudos, estava presente uma reflexão mais detida sobre a cultura, a literatura e a educação, questões que há muito vinham sendo levantadas por outros estudiosos, em especial por Richard Hoggart e Raymond Williams

Na academia brasileira, desde meados da década de 1980, a história social consolidou seu projeto acadêmico em diversas instâncias nacionais e internacionais, destacando-se os estudos sobre as "culturas de classe", as relações sociais de trabalho, incluindo as dimensões culturais de escravidão e a atuação dos trabalhadores, escravos, livres e libertos como sujeitos históricos em

TrabalhoNecessário - www.uff.br/trabalhonecessario; Ano 12, № 18/2014. 


\section{Trabalhonecessário}

Issn: 1808 - 799X

ano 12 , no $18-2014$

luta no processo de formação da classe trabalhadora no Brasil. Em especial, as obras e as perspectivas de E. P. Thompson encontraram maior ressonância entre os pesquisadores que pretendiam rediscutir a tradição culturalista e a ortodoxia marxista. Categorias como agência, fazer-se, economia moral da multidão e costumes comuns foram escolhidas para nortear, e até certo ponto reorganizar, a história social brasileira da cultura e do trabalho. Apoiado neste instrumental analítico, o campo queria instituir, no país, através de consistente pesquisa empírica, uma vigorosa "história vista de baixo". 7

A opção por E. P. Thompson e pelas propostas da história social e cultural inglesa foi ao encontro de uma série de especificidades conjunturais, que se relacionavam com o processo de redemocratização do país. Na sociedade civil, por sua vez, a reorganização dos movimentos sociais e sindicais também foi muito importante para revigorar o interesse dos analistas pelo mundo do trabalho.

Ainda foi significativo o "ressurgimento" dos movimentos sociais, que amplificavam as vozes das mulheres, dos negros, dos homoafetivos e de outras minorias que buscavam o reconhecimento de sua atuação política e social, de sua cidadania.

Em 1995, Silvia Lara publicou um representativo balanço sobre a historiografia da escravidão que buscou seus referenciais analíticos nas obras do

\footnotetext{
${ }^{7}$ Consultar, por exemplo: BATALHA, Cláudio H. M. A historiografia da classe operária no Brasil: trajetórias e tendências, in Marcos C. de Freitas (org.). Historiografia brasileira em perspectiva. São Paulo, Contexto, 2003, p. 145-58; BATALHA, Claudio. Identidade da classe operária no Brasil: atipicidade ou legitimidade?. Revista Brasileira da História, vol. 12, oㅡ 23/24, set. 1991/ago. 1992, p. 111-24; CHALHOUB, Sidney, FONTES, Paulo. História social do trabalho, história pública. Perseu: história, memória e política, no 4, ano 3, 2009, p. 219-28; LARA, Silvia H.

"Blowin'in the wind: E. P. Thompson e a experiência negra no Brasil". Projeto História, oㅡ 12, 1995, pp. 43-56; LARA, Silvia H. Campos da violência: escravos e senhores na Capitania do Rio de Janeiro, 1750-1808. Rio de Janeiro, Editora Paz e Terra, 1988; SLENES, Robert W. Na senzala, uma flor: esperanças e recordações na formação da família escrava - Brasil Sudeste, século XIX, $3^{a}$ imp. Rio de Janeiro, Nova Fronteira, 1999; MAC CORD, Marcelo. Andaimes, casacas, tijolos e livros: uma associação de artífices no Recife, 1836-1880". Tese de doutorado. Campinas, IFCH/UNICAMP, 2009; NEGRO, Antonio Luigi, GOMES, Flávio dos Santos. Além de senzalas e fábricas: uma história social do trabalho, Tempo Social: revista de sociologia da USP, vol. 18, no 1, 2006, pp. 217-40.
} 


\section{Trabalhonecessário}

Issn: 1808 - 799X

ano 12 , no $18-2014$

marxista inglês. Segundo a autora, a orientação thompsoniana permitiu que os pesquisadores criassem novas abordagens sobre a temática e transformassem radicalmente sua compreensão. A categoria "agência", por exemplo, possibilitou que fossem observadas as expectativas e as ações dos próprios cativos na formação de suas famílias, na construção de seus espaços de autonomia e de sociabilidade, na montagem de suas estratégias por alforria e na elaboração de novos significados para a liberdade (LARA, 1995). Na medida em que os historiadores sociais entenderam que os escravos eram sujeitos históricos, utilizaram as próprias experiências e percepções do cativeiro para reconstruir as identidades sociais dos africanos e seus descendentes.

Concorrentemente aos renovadores estudos sobre a história da escravidão, também foram investigadas as experiências dos trabalhadores assalariados que viveram nos períodos de desenvolvimento e de consolidação da indústria nacional. Um balanço historiográfico feito por Claudio Batalha, publicado no ano de 2003, demonstrou que as ideias de E. P. também vinham sendo utilizadas, desde a década de 1980, para repensar e redimensionar a história da classe operária brasileira. Na medida em que a categoria classe era entendida como algo socialmente construído, nossos pesquisadores conseguiam demonstrar, por meio de sólida base empírica, importantes especificidades espaços-temporais na organização dos trabalhadores nacionais que lutaram por direitos no transcorrer do século passado. Vale registrar que, como resultado de suas investigações, os novos estudos relativizaram as problemáticas noções de "atipicidade" e "incompletude" da formação do operariado brasileiro, teses clássicas que marcaram a bibliografia especializada das décadas de 1960 e 1970 (BATALHA, 2003, 1992).

Se entre os historiadores de ofício a presença das contribuições de E. P. Thompson está bastante consolidada, no campo da história da educação, no entanto, a apropriação da obra e das perspectivas de Thompson são ainda pontuais. Em 2005, Luciano Mendes de Faria Filho já sublinhava a sua

TrabalhoNecessário - www.uff.br/trabalhonecessario; Ano 12, № 18/2014. 


\section{Trabalhonecessário}

Issn: 1808 - 799X

ano 12 , no $18-2014$

inexpressiva influência no campo. Mais recentemente, juntamente com Liane Bertucci e Marco Aurélio Taborda, Luciano Mendes procurou reforçar, por meio do livro Edward P. Thompson: história e formação, a importância dos usos do autor britânico para fomentar, no país, investigações em história social da educação.

Tendo como bússola os instrumentais teóricos e metodológicos oferecidos pela história social e cultural inglesa, a publicação faz algumas apostas. Entre elas, tomar a cultura escolar como auspicioso objeto de estudo, pois a mesma é formada a partir das tensões entre as experiências dos sujeitos que convivem com e na escola e os projetos políticos educacionais oficiais. Neste viés analítico, a educação formal e os estabelecimentos escolares deixam de ser encarados como simples elementos superestruturais ou reprodutores de um "saber universal". Ou seja, espaços de um absoluto domínio ideológico sobre seu público. Movido por esta percepção, o investigador pode compreender as complexidades do processo histórico da escolarização, marcado por conflitos e/ou confluências com outras tradições educativas - que são informadas, entre outros elementos, por práticas culturais e costumeiras. A partir desta perspectiva, é fundamental pesquisar a escola e sua relação com a cultura e a sociedade.

A partir do que foi acima sugerido, Edward P. Thompson: história e formação desdobra outro caminho investigativo. O pesquisador, municiado pela história social inglesa, também pode lançar seu olhar para as múltiplas temporalidades sociais e escolares, temática que se cruza com o processo histórico da escolarização e, principalmente, com os rigorosos tempos que são impostos pelas sociedades capitalistas ao mundo do trabalho. As suas perspectivas também tem grande valia para os projetos de pesquisa que pretendem estudar os campos de força que produzem as leis educacionais. Isto porque, apesar da hegemonia das "classes dominantes", nem sempre seus interesses prevalecem ou se impõe na arena legislativa. As leis educacionais, portanto, não podem ser entendidas como algo ensimesmado, isoladas de suas condições de produção, mas como fruto das lutas e das mais diversas demandas

TrabalhoNecessário - www.uff.br/trabalhonecessario; Ano 12, № 18/2014. 


\section{Trabalhonecessário}

Issn: 1808 - 799X

ano 12, no $18-2014$

que as forjaram. Junto disto, o investigador em história social da educação ainda pode atentar para a execução dos códigos que regulam a educação formal, pois, além de sofrerem interpretações, nem sempre são total ou parcialmente respeitados nas instâncias mais cotidianas da vida.

Nos últimos anos, o campo tem acolhido alguns projetos de pós-graduação atentos às experiências dos trabalhadores que criaram estratégias próprias de escolarização, lutaram pelo seu aperfeiçoamento profissional e discutiram o respeito às costumeiras hierarquias artesanais. Para os séculos XIX e XX, por exemplo, encontramos investigações que analisam as instituições educativas, em seus diversos níveis; as culturas, os espaços e os tempos escolares; as experiências de crianças, alunos e professores em várias dimensões e relações pedagógicas; os cursos noturnos e as práticas de educação de trabalhadores; as vivências de artífices especializados, livres, libertos e escravos, durante a vigência do escravismo. Organizados em sociedades de auxílio mútuo, eles utilizavam o aperfeiçoamento técnico adquirido nas oficinas e a instrução alcançada em aulas noturnas para conquistarem respeitabilidade pública e mobilidade social ascendente. A educação escolar era apropriada pelos subalternos como arma de reconhecimento de sua cidadania (MAC CORD, 2010).

Tendo em vista uma ampla agenda de pesquisa, o desejo de fortalecimento da história social brasileira da educação e a pequena ressonância do marxista inglês no campo, certamente ainda há muito trabalho por fazer. Em nossa área, correndo o risco de generalização, podemos identificar duas correntes intelectuais hegemônicas. Desde o final da ditadura civil-militar, em meados da década de 1980, os estudos têm sido predominantemente realizados por grupos "francófilos", que acionam em suas investigações alguns pressupostos de autores como Roger Chartier, Michel de Certeau, Pierre Bourdieu e Michel Foucault. A outra corrente, que mantém certo monopólio sobre as temáticas vinculadas tradicionalmente à história social, optou por um marxismo ortodoxo como ferramenta explicativa, ainda que tal perspectiva não mais possua o mesmo viço das décadas de 1960 e

TrabalhoNecessário - www.uff.br/trabalhonecessario; Ano 12, № 18/2014. 


\section{Trabalhonecessário}

Issn: 1808 - 799X

ano 12 , no $18-2014$

1970. Absolutamente, é óbvio que são legítimas ambas as escolhas acadêmicas. Contudo, em texto escrito com Marcelo Mac Cord, problematizamos alguns excessos subjetivistas que marcam os estudos culturais de inspiração francesa. Da mesma forma, relativizamos o aprisionamento da cultura e do sujeito histórico às determinações estritamente econômicas. Com Raymond Williams e E. P. Thompson, reafirmamos o princípio epistemológico que considera a materialidade da cultura, e a categoria da totalidade histórica, como instrumentos de análise fundamental para o pensamento marxiano, defendendo a tese de que a cultura e a sociedade são indissociáveis (WILLIAMS, 2011a, 2011b; THOMPSON, 2001).

Em outra perspectiva, é preciso reconhecer que na historiografia especializada, a categoria "educação" ainda mantém profundos vínculos com certas perspectivas criadas pelo pensamento iluminista. Alimentada pela perspectiva ilustrada que naturalizou o viés civilizatório da educação formal, a historiografia brasileira mais tradicional quase sempre atentou exclusivamente para os projetos escolares estatais, que foram concebidos e administrados pelas elites letradas e proprietárias. Neles, os "de baixo" sempre aparecem como meros consumidores de produtos culturais "alienantes", impostos pela classe dominante.

Vale destacar que não estamos nem de longe propondo o abandono dos estudos sobre a escola como instituição de educação, em seus moldes mais clássicos. Entretanto, é necessário avançar na proposição de novos olhares sobre o mesmo problema de pesquisa, bem como novos objetos e abordagens. Podemos pesquisar outras formas e práticas de ensino-aprendizagem vivenciadas fora das salas de aula, nos espaços sociais plurais, mas que também estão repletas de tensões políticas e sociais. Por exemplo, pensamos aqui no tirocínio artesanal das oficinas; no âmbito do trabalho urbano e rural; nas heterogêneas formas de relações familiares; nas práticas difusas e informais de transmissão de valores; nos meios de comunicação de massa; no teatro; nas redes e tecnologias de informação, etc., etc. Por meio de relações interpessoais e interclassistas, apreendem-se técnicas, saberes, culturas, modos de viver, e de

TrabalhoNecessário - www.uff.br/trabalhonecessario; Ano 12, № 18/2014. 


\section{Trabalhonecessário}

Issn: 1808 - 799X

ano 12 , no $18-2014$

conduta social, pelos quais ocorre a construção permanente e inacabada de identidades sociais, geracionais, sexuais, de gênero, interétnicas e raciais. Precisamos, sim, viabilizar a aproximação dos historiadores da educação com os que labutam na história social brasileira da cultura e do trabalho, atualizar a nossa bibliografia de referência e as opções teórico-metodológicas, bem como aprofundar o intercâmbio com os estudos do campo de Trabalho e Educação.

Afinal, a meu ver, categorias caras ao materialismo histórico e ao pensamento de Karl Marx, como classe, lutas de classe, cultura, formação e experiência e consciência, e a compreensão da História como disciplina do contexto, do processo e do movimento, não podem ser abandonadas em favor de uma narrativa "mais agradável", uma aula mais amena ou pela adesão a "última moda" teórica do bas fond acadêmico. Com E. P. Thompson, a História Social da Educação, como programa de pesquisa, pode ser capaz de enfrentar a hegemonia de um modo de pensar a História pela ótica exacerbada de um

"culturalismo sem classes" e/ou de uma visão idealista de um "mundo sem referente", de um "mundo como texto" (WILLIAMS, 2001a).

Para finalizar essa breve reflexão, gostaria, então, de retornar às palavras iniciais e reiterar a perspectiva emancipatória que está presente na prática teórica e política do historiador inglês. Para tanto, nada melhor que relembrar alguns de seus argumentos. Referindo-se ao seu clássico estudo sobre William Morris (1955), E. P. Thompson destacou que a história -, e podemos afirmar também, a educação -, só tem sentido como prática ativa em prol da transformação da experiência social, da própria vida humana:

\footnotetext{
"Se quisermos salvar as pessoas do cada vez mais disseminado veneno da morte, precisamos conquistá-las para a vida. Não podemos esperar que apareça um novo tipo de pessoa até que o socialismo tenha triunfado, tanto quanto não podemos esperar que o marxismo surja dentro de uma sociedade comunista. Precisamos mudar as pessoas agora, pois aí está a essência do nosso trabalho cultural." (Thompson, 1998, p. 98).
} 


\section{Trabalhonecessário}

Issn: 1808 - 799X

ano 12, no $18-2014$

\section{Referências}

ANDERSON, Perry. A crise da crise do marxismo. Introdução a um debate contemporâneo. Tradução de Denise Bottmann, São Paulo, Brasiliense, $2^{\underline{a}}$ Ed., 1985.

BATALHA, Cláudio H. M. A historiografia da classe operária no Brasil: trajetórias e tendências, in Marcos C. de Freitas (org.). Historiografia brasileira em perspectiva. São Paulo, Contexto, 2003, p. 145-58.

- Identidade da classe operária no Brasil: atipicidade ou legitimidade? Revista Brasileira da História, vol. 12, oㅡ 23/24, set. 1991/ago. 1992, p. 111-124.

BERTUCCI, Liane M.; FARIA FILHO, Luciano M. TABORDA, Marcus A. Edward P. Thompson: história e formação. Belo Horizonte, Editora UFMG, 2010. BURKE, Peter. A escrita da história: novas perspectivas. São Paulo, Editora da UNESP, 1992.

CHALHOUB, Sidney; FONTES, Paulo. História social do trabalho, história pública. Perseu: história, memória e política, n 4, ano 3, 2009, p. 219-28.

FARIA FILHO, Luciano M. Fazer história da educação com E. P. Thompson: trajetórias de um aprendizado, in Luciano M. de Faria Filho (org.), Pensadores sociais e História da Educação. Belo Horizonte, Autêntica, 2005.

GONDRA, José; SCHUELER. Alessandra. Educação, poder e sociedade no Império Brasileiro. (Col. Biblioteca Básica de Educação, v. 1), São Paulo, Cortez, 2008.

HOGGART, Richard. The uses of literacy. Londres, Chatto and Windus. 1957.

LARA, Silvia H. Blowin'in the wind: E. P. Thompson e a experiência negra no Brasil. Projeto História, no 12, 1995, pp. 43-56.

Campos da violência: escravos e senhores na Capitania do Rio de Janeiro, 1750-1808. Rio de Janeiro, Editora Paz e Terra, 1988. 


\section{Trabalhonecessário}

Issn: 1808 - 799X

ano 12 , no $18-2014$

MAC CORD, Marcelo. Andaimes, casacas, tijolos e livros: uma associação de artífices no Recife, 1836-1880. Tese de doutorado em História Social. Programa de Pós-Graduação em História, Universidade Estadual de Campinas, IFCH/UNICAMP, 2010.

MATTOS, Marcelo Badaró. A trajetória de E. P. Thompson: engajamento político.

E P. Thompson e a tradição de crítica ativa do materialismo histórico. Rio de Janeiro, UFRJ, 2012.

NEGRO, Antonio Luigi; GOMES, Flávio dos Santos. Além de senzalas e fábricas: uma história social do trabalho, Tempo Social: revista de sociologia da USP, vol. 18, ำ 1, 2006, pp. 217-40.

PALMER, Bryan. Edward Thompson: objeções e oposições. Tradução: Klauss Brandini Gerhardt, Rio de Janeiro, Paz e Terra, 1996.

REIS, João José. Rebelião escrava no Brasil. A história do levante dos malês em 1835. São Paulo, Companhia das Letras, 2003.

SAVIANI, Demerval, LOMBARDI, José Claudinei, SANFELICE, José Luis (orgs.), História e história da educação: o debate teórico metodológico atual. Campinas, Autores Associados/HISTERBR, 1998.

SLENES, Robert W. Na senzala, uma flor: esperanças e recordações na formação da família escrava - Brasil Sudeste, século XIX, 3로 imp. Rio de Janeiro, Nova Fronteira, 1999.

TABORDA, Marcus A. O pensamento de Edward Palmer Thompson como programa para a pesquisa em história da educação: culturas escolares, currículo e educação do corpo. Revista Brasileira de História da Educação, oํ 16, 2008.

THOMPSON, Edward. Educação e experiência. Os Românticos. A Inglaterra na era revolucionária. Tradução: Sérgio Moraes Rêgo Reis, Rio de Janeiro, Civilização Brasileira, 2002.

As peculiaridades dos ingleses e outros artigos. Organizadores: Antonio Luigi Negro e Sergio Silva, Campinas, São Paulo, Editora da UNICAMP, 2001.

TrabalhoNecessário - www.uff.br/trabalhonecessario; Ano 12, № 18/2014. 


\title{
Trabalhonecessário
}

\author{
Issn: 1808 - 799X \\ ano 12 , no $18-2014$
}

. Costumes em Comum. Tradução: Rosara Eichemberg, São

Paulo, Companhia das Letras, 1998.

. Making History. Writtings on History and Culture. New

York: New York Press, 1995.

. Senhores e caçadores. Tradução: Denise Bottmann, Rio de Janeiro, Paz e Terra,1997.

A formação da classe operária inglesa: a árvore da liberdade, vol. 1. Tradução: Denise Bottmann, Rio de Janeiro, Paz e Terra, 1987.

A miséria da teoria ou um planetário de erros. Tradução de Waltensir Dutra, Rio de Janeiro, Paz e Terra, 1981.

. Tradición, revuelta y consciência de clase: La sociedad inglesa preindustrial. Barcelona, 1979.

William Morris: romantic to revolucionary. PM Press \& Merlin

Press, 1955.

VEIGA, Cynthia Greive; FONSECA, Thais Nívia de Lima (orgs.), História e historiografia da educação no Brasil. Belo Horizonte, Editora Autêntica, 2003. WILLIAMS, Raymond. Base e superestrutura na teoria da cultura marxista.

Cultura e materialismo. Tradução: André Glaser, São Paulo, Unesp, 2011a. . Cultura e sociedade. De Coleridge a Orwell, 1780-1950.

Tradução de Vera Joscelyne, Rio de Janeiro, Petrópolis, Vozes, 2011b. Marxismo e literatura. Tradução de Waltensir Dutra, Rio de Janeiro, Zahar, 1979.

Recebido em maio de 2014 Aprovado em junho de 2014 